\title{
Maternal Dissatisfaction During the Postpartum Recuperation Period is an Independent Risk Factor for Postpartum Depression after Caesarean Section in China - A Prospective Cohort Study
}

\section{Liping Li}

The third affiliated hospital of SunYat-Sen University

\section{Chaojin Chen}

The third affiliated hospital of SunYat-Sen University

Yiying You

The third affiliated hospital of SunYat-Sen University

Mierzhati Muhetaer

The third affiliated hospital of SunYat-Sen University

Fei Huang

The third affiliated hospital of SunYat-Sen University

Jingru Pan

The third affiliated hospital of SunYat-Sen University

Shaoli Zhou

The third affiliated hospital of SunYat-Sen University

\section{Ziqing Hei}

The third affiliated hospital of SunYat-Sen University

\section{Chenfang Luo}

The third affiliated hospital of SunYat-Sen University

\section{Yanling Wang ( $\nabla$ wyl-5120@163.com )}

The third affiliated hospital of SunYat-Sen University

\section{Research Article}

Keywords: Postpartum depression, Risk factors, Doing the month, Maternal dissatisfaction, Caesarean section, Pain

Posted Date: August 12th, 2021

DOl: https://doi.org/10.21203/rs.3.rs-792984/v1 
License: (c) (i) This work is licensed under a Creative Commons Attribution 4.0 International License. Read Full License 


\section{Abstract}

Background: Postpartum depression (PD) is a common disorder associated with severe adverse infant and maternal outcomes, which is becoming an important public health problem. However, studies on the clinical relevance of anesthesia and PD are very limited. This study aimed to examine risk factors for PD amongst Chinese parturients of caesarean section from the perspective of anesthesiology, especially during the standard Chinese postpartum recuperation period known as "doing the month".

Methods: Prospective cohort study of 125 women who received caesarean sections aged from 21 to 46 years. The Edinburgh Postnatal Depression Scale were evaluated at the day before caesarean section and 6 weeks postpartum. Demographic, clinical, and treatment, including postoperative prognostic data and conditions during "doing the month", were recorded and compared between PD and non-PD groups. Univariable and multivariable logistic regression methods were used to explore the risk factors associated with the occurrence of PD.

Results: 44 (34.9\%) patients were diagnosed PD at 6 weeks postpartum. Occurrence of PD was associated with postoperative pain, pruritus, dissatisfaction with "doing the month". Multivariate regression analysis showed that lumbago (OR 5.68,95\% $\mathrm{Cl} 1.69-19.06 ; \mathrm{p}=0.005)$, maternal total dissatisfaction during "doing the month" $(\mathrm{OR} 6.87,95 \% \mathrm{Cl}$ 2.48-19.04; $\mathrm{p}=0.001)$, and dissatisfaction with mother in-law during "doing the month" $(\mathrm{OR} 3.22,95 \% \mathrm{Cl} 1.43-16.16 ; \mathrm{p}=0.020)$ were independent risk factors for $\mathrm{PD}$, while mild activity pain was independent protective factor for PD 6 weeks postpartum (OR $0.018,95 \% \mathrm{Cl} 0.01-0.25 ; \mathrm{p}=0.003)$.

Conclusions: PD was a commonly experienced psychological disorders for women undergoing caesarean section. Postpartum lumbago, maternal total dissatisfaction and dissatisfaction with mother in-law during "doing the month" and mild activity pain were main factors for PD at 6 weeks postpartum.

\section{Background}

Postpartum depression (PD) is common and has been linked to negative health-related behaviors and adverse infant and maternal outcomes, including physical and mental disease of mothers, psychological and developmental disturbances in babies, and confer a social burden on families and communities in both developed and developing countries ${ }^{[1-3]}$. It was recognized as one of the major contributors of pregnancy-related morbidity and mortality.

The specific etiology of PD is unclear; however, risk factors include low educational attainment or low socioeconomic status, low levels of social support, socio-environmental distress, history of mental illness, preterm birth, and a traumatic birth experience were reported ${ }^{[4,5]}$. And accompanied with the reduced adolescent birth rate, fewer women experiencing stressful life events in the year preceding birth, and increased antidepressant prescriptions, the prevalence of PD markedly declined ${ }^{[6]}$. But still nearly $60 \%$ of women with depressive symptoms did not receive a clinical diagnosis, and $50 \%$ of women with a 
diagnosis did not receive any treatment ${ }^{[7]}$. Moreover, in many countries, significant barriers to preliminary clinical understanding and recognition of PD exist, contributing to underdiagnosis and undertreatment. There is an urged need to deeply understand the postpartum psychological aftermath and find reasonable interventions to prevent and treat psychological disorders, improving maternal and familial wellbeing.

Major cross-cultural and physical quality differences contribute to different concepts of postpartum recovery ${ }^{[8]}$. In China, commonly after caesarian section women undergo a period of recuperation known as"doing the month" (in Chinese "Zuo yue zi"). This is a specific regime for Chinese parturients, either at home or in a maternity hotel, postpartum for 30 to 42 days. Women "doing the month" have specially prepared nutritious meals, receive professional breastfeeding guidelines and the postpartum recovery service provides guidelines to manage their emotions and for physical activity to restore their shape and energy. "Doing the month" can help new mothers to successfully make the physical and psychological transition of motherhood and may reduce their physical and psychological health problems ${ }^{[9]}$.

The birth experience may influence postpartum mood disorders either from birth or with onset some months postpartum ${ }^{[10]}$. There is a strong relation between delivery mode and PD. Normal vaginal delivery women have significantly lower Edinburgh Postnatal Depression Scale (EPDS) scores than those of caesarian section women ${ }^{[11]}$. Compared to general anesthesia, regional anesthesia for cesarean delivery is associated with decreased odds of severe PD requiring hospitalization and suicidal ideation ${ }^{[12,13]}$. It is even recognized that acute post-cesarean pain is associated with slight reductions in the quality of inhospital exclusive breastfeeding, more severe PD status and increased length of stay ${ }^{[14]}$. Prophylactic use of dexmedetomidine can reduce the PD symptoms amongst women undergoing cesarean section ${ }^{[15]}$. Esketamine can serve rapid life-saving improvement in PD with severe suicidal ideation ${ }^{[16]}$. So, anesthesiologists need to carry the burden of optimal perioperative management in choice of anesthesia and analgesia patterns to prevent maternal outcomes from both physical and mental aspects.

However, studies on the clinical relevance of anesthesia and PD are very limited. This study aims to investigate the occurrence and risk factors of PD amongst Chinese parturients of caesarean section from the perspective of anesthesiology, especially during "doing the month".

\section{Methods}

\section{Study design and participants}

Inclusion criteria for this study were as follows: women aged from 21 to 45 years, American Society of Anesthesiologists (ASA) grade I- II, gestation age > 38 weeks, scheduled for cesarean delivery under combined spinal and epidural anesthesia from July 2019 to October 2019. All accepted Enhanced Recovery After Surgery (ERAS) management which includes enhanced perioperative education, being kept warm during surgery, avoiding overhydration, and early oral intake ${ }^{[17]}$. Exclusion criteria were as 
follows: history of severe psychological problems (depression, mania, or bipolar affective disorder); history of cardiac or hepatic disease; contraindications to combined spinal and epidural anesthesia (CSEA); obstetric complications (massive haemorrhage, placenta implantation, amniotic fluid embolism, etc.); contraindications to drugs in this study; opioid dependence; undergoing other operations; participated in other clinical research; refused to participate, and lost to follow up in the study.

\section{Data collection}

EPDS was used to diagnose depression or anxiety. PD was defined as an EPDS score above 13. Prepartum and postpartum evaluation to EPDS were performed at the day before caesarean section and 6 weeks postpartum. The primary outcome was the occurrence of PD at 6 weeks postpartum.

Standard data collected during cesarean operations were also collected including: Dosages of Ropivacaine (mg), Dexmedetomidine, Phenylephrine, and Uterine contraction drugs; Hypotension; Chills; Nausea; Vomit; Anesthesia time (min); Time of operation (min); Input crystal fluid (ml); Urine (ml); Bleeding volume $(\mathrm{ml})$.

As well as standard clinical data, the study collected a number of 10-point visual analogue scales assessing pain tolerance, occupational stress, pruritus and dissatisfaction with ERAS ("doing the month"). Demographic characteristics and preoperative data were collected including age, body mass index (BMI), ASA classification, gestation and delivery history, occupation, education level, history of previous disease, hospitalization expenses, hospitalization length, pain tolerance and occupational stress. Perioperative data including anesthesia time, operation time, perinatal adverse events (intraoperative hypotension; drug allergy; massive bleeding), intraoperative medications; postoperative data including analgesia programs, postpartum pain, nausea, and pruritus at 24 hours and 48 hours after surgery, incidence of postpartum adverse events (postpartum hemorrhage, wound infection, mastitis, fever, abdominal distension), and neonatal complications etc. Data for 6 weeks postpartum included dissatisfaction during "doing the month" as shown in Table 1, including dissatisfaction with place of "doing the month" or family occupational support, were recorded. Pain tolerance, occupational stress, and degree of dissatisfaction were evaluated by visual analog scale (VAS). 
Table 1

A multiple-choice questionnaire for dissatisfaction during "doing the month" assessment.

\begin{tabular}{|l|}
\hline 1. Do you feel dissatisfaction during "doing the month"? Yes No \\
\hline 2. What do you feel dissatisfaction with during "doing the month"? \\
A. Dissatisfaction with place of "doing the month" \\
B. Dissatisfaction with role transition to a new mother/or being a mother again \\
C. Dissatisfaction with mother-in-law \\
D. Dissatisfaction with husband \\
E. Dissatisfaction with baby for difficult to take care
\end{tabular}

As 6 months postpartum coincided with the outbreak of COVID-19, we telephoned to follow-up whether the epidemic pneumonia influenced their psychological state. They were asked: 1 . Do you feel fear or anxiety about COVID-19? They were asked to rate this out of 10. 2. What do you worry about, fear of infection with the virus or others?

The patient's preoperative and intraoperative conditions were recorded by the chief anesthesiologist; the postoperative situation was followed up by the anesthesiologist in charge of data collection.

\section{Statistical analysis}

Continuous and categorical variable data are presented as number (percentage) or mean \pm standard deviation. One-sample Kolmogorov-Smirnov tests were used to test the normality of measurement data. Abnormally distributed measurement data are shown as median and range. A 2-tailed independent sample $t$-test and Wilcoxon rank sum test were used to compare normally distributed measurement data and abnormally distributed measurement data, respectively. Pearson's chi-squared tests or Fischer's exact tests were used as appropriate to analyze enumeration data. Variables that were significantly different between PD and non-PD groups were included in logistic regression analyses for univariate and multivariate analyses. Significance was set at $P<0.05$. All statistical analyses were performed using SPSS 23 (IBM, Chicago, IL) software.

\section{Results}

\section{Incidence of PD at 6 weeks postpartum}

According to the inclusion and exclusion criteria, we included 125 parturients in the final analysis (Fig. 1). The overall incidence of PD at 6 weeks postpartum was $34.9 \%(44 / 125)$, while prenatal depression was $5.6 \%(7 / 125)$. 
Table 2

Demographics and clinical characteristics.

\begin{tabular}{|c|c|c|c|c|}
\hline Variable & & $\begin{array}{l}\text { Non-PD }(n= \\
81)\end{array}$ & $\begin{array}{l}P D(n= \\
44)\end{array}$ & $\begin{array}{l}P \\
\text { value }\end{array}$ \\
\hline Age (Year) (mean [SD]) & & $33.6(4.3)$ & $33.3(4.0)$ & 0.831 \\
\hline \multirow[t]{2}{*}{ Age (Year) (n [\%]) } & $<35$ & $50(61.7)$ & $27(61.4)$ & 1.000 \\
\hline & $\geq 35$ & $31(38.3)$ & $17(38.6)$ & \\
\hline BMI (mean [SD]) & & $26.5(3.10)$ & $27.1(3.3)$ & 0.445 \\
\hline \multirow[t]{2}{*}{ ASA (n [\%]) } & 1 & $8(9.9)$ & $2(4.5)$ & 0.330 \\
\hline & II & $74(90.1)$ & $42(95.5)$ & \\
\hline \multirow[t]{4}{*}{ Occupation (n [\%]) } & $\begin{array}{l}\text { Professional and technical } \\
\text { staff }\end{array}$ & $26(32.1)$ & $14(31.8)$ & 0.982 \\
\hline & Public officer & $33(40.7)$ & 18(40.9) & \\
\hline & Business, service personnel & 15(18.6) & $9(20.5)$ & \\
\hline & Other occupations & $7(8.6)$ & $3(6.8)$ & \\
\hline \multirow[t]{3}{*}{ Family income (CNY) (n [\%]) } & $<150$ thousand & $37(45.7)$ & 14(31.8) & 0.238 \\
\hline & $150-300$ thousand & $38(46.9)$ & $22(50.0)$ & \\
\hline & $\geq 400$ thousand & $6(7.4)$ & $8(18.2)$ & \\
\hline \multirow[t]{3}{*}{ Education (n [\%]) } & High school and below & $3(3.7)$ & $3(6.8)$ & 0.323 \\
\hline & Undergraduate & $67(82.7)$ & $39(88.6)$ & \\
\hline & Postgraduate & 11(13.6) & $2(4.6)$ & \\
\hline \multirow[t]{2}{*}{ Gravidity (n [\%]) } & Once & $24(29.6)$ & 18(40.9) & 0.403 \\
\hline & Twice and above & $57(70.4)$ & $26(59.1)$ & \\
\hline \multirow[t]{2}{*}{ History of lumbago (n [\%]) } & No & $57(70.4)$ & $32(72.7)$ & 1.000 \\
\hline & Yes & $24(29.6)$ & $12(27.3)$ & \\
\hline \multirow[t]{3}{*}{ Other disease history (n [\%]) } & $\begin{array}{l}\text { Pregnancy-induced } \\
\text { hypertension }\end{array}$ & $2(2.5)$ & $2(4.6)$ & 0.576 \\
\hline & GDM & $15(18.5)$ & $4(9.1)$ & \\
\hline & Antepartum depression & $5(6.2)$ & $2(4.6)$ & \\
\hline History of anesthesia (n [\%]) & No & $29(35.8)$ & $21(47.7)$ & 0.354 \\
\hline
\end{tabular}

Mild: VAS 1-3; moderate: VAS 4-6; severe: VAS 7-10; CNY: China Yuan. 


\begin{tabular}{|lllll|}
\hline Variable & & Non-PD $(n=$ & PD $(n=$ & $P$ \\
$44)$ & value \\
\hline & Yes & $52(64.2)$ & $23(52.3)$ & \\
\hline Pain tolerance (VAS) (n [\%]) & Mild & $42(51.9)$ & $18(40.9)$ & 0.703 \\
\hline & Moderate & $34(42.0)$ & $22(50.0)$ & \\
\hline & Severe & $5(6.1)$ & $4(9.1)$ & \\
\hline $\begin{array}{l}\text { Occupational stress (VAS) (n) } \\
\text { [\%]) }\end{array}$ & Mild & $9(11.1)$ & $3(6.8)$ & 0.625 \\
\hline & Moderate & $39(48.1)$ & $26(59.1)$ & \\
\hline & Severe & $33(40.8)$ & $15(34.1)$ & \\
\hline Mild: VAS 1-3; moderate: VAS 4-6; severe: VAS 7-10; CNY: China Yuan. & & \\
\hline
\end{tabular}

\section{Demographics and clinical characteristics}

The median age of the 125 patients was 33.6 years, ranging from 25 years to 43 years. Of the sample, 48 women were aged 35 years or more and hence at higher risk for complications, 84 women were delivering their second or second above child and 44 their first. Preoperative disease history was present in nearly half of parturients with lumbago being the most common disease (Table 2). We collected and analyzed BMI, ASA degree, general family conditions, parity, occupational stress, pain tolerance and other related factors, and found that there was no significant difference between PD and non-PD groups.

\section{Intraoperative data screening}

Intraoperative parameters about anesthetic usage, reaction to anesthesia and corresponding treatments, and general situations during operation may influence parturient psychological state. But there were no differences on a range of intraoperative physical measures for PD.

\section{Postoperative data screening}

Postpartum physical discomfort frequently resulted in parturients' psychological symptoms. Postpartum pain, nausea and vomit, and mastitis were common complications. We observed that PD was associated with rest pain $(P=0.007)$, activity pain $(P=0.013)$, and pruritus $(P=0.039)$ at $48 \mathrm{~h}$ after caesarean section, as well as lumbago at 6 weeks postpartum $(P=0.049)$. Pairwise comparison found that the incidence of PD in parturients with mild pain was significantly lower than that without pain or moderate pain, regardless of pain during activity or at rest (Table 3 ).

Taking care of infants is a very hard job that disturbs the previous rhythm of life. In China, besides maternity matron, mothers or mothers-in-law are frequently in charge of the company and care of parturient during "doing the month", so there is potential for conflict between the parturient and her 
mother or mother-in-law. Fischer's exact tests found that maternal total dissatisfaction during "doing the month" was strongly related to PD $(P=0.002)$. The dissatisfaction with places of "doing the month" $(P=$ $0.001)$, mother-in-law $(P=0.002)$, and husband $(P=0.001)$ were three main reasons for parturient to be depression (Table 4) (Fig. 2). 
Table 3

Postoperative data screening (reported as $\mathrm{n}(\%)$, unless otherwise noted).

\begin{tabular}{|c|c|c|c|c|}
\hline Variable & & Non-PD $(n=81)$ & $P D(n=44)$ & $P$ \\
\hline \multirow[t]{3}{*}{ Resting pain (24h) } & None & $12(14.8)$ & $12(27.3)$ & 0.151 \\
\hline & Mild & $62(76.5)$ & $24(54.5)$ & \\
\hline & Moderate & $7(8.7)$ & $8(18.2)$ & \\
\hline \multirow[t]{3}{*}{ Resting pain (48h) } & None & $12(14.8)$ & 18(40.9) & $0.007 *$ \\
\hline & Mild & $61(75.3)$ & 18(40.9) & \\
\hline & Moderate & $8(9.9)$ & $8(18.2)$ & \\
\hline \multirow[t]{3}{*}{ Activity pain (24h) } & None & $9(11.1)$ & $11(25.0)$ & 0.213 \\
\hline & Mild & $31(38.3)$ & 18(40.9) & \\
\hline & Moderate & $41(50.6)$ & $15(34.1)$ & \\
\hline \multirow[t]{3}{*}{ Activity pain (48h) } & None & $7(8.6)$ & $15(34.1)$ & $0.013^{*}$ \\
\hline & Mild & $57(70.4)$ & $20(45.5)$ & \\
\hline & Moderate & $17(21.0)$ & $9(20.4)$ & \\
\hline \multirow[t]{2}{*}{ Nausea (24h) } & None & $79(97.5)$ & $39(88.6)$ & 0.236 \\
\hline & Mild & $2(2.5)$ & $5(11.4)$ & \\
\hline \multirow[t]{2}{*}{ Nausea (48h) } & None & $79(97.5)$ & $42(95.5)$ & 1 \\
\hline & Mild & $2(2.5)$ & $2(4.5)$ & \\
\hline \multirow[t]{3}{*}{ Pruritus (24h) } & None & $44(54.3)$ & 14(31.8) & 0.063 \\
\hline & Mild & $25(30.9)$ & 15(34.1) & \\
\hline & Moderate & $12(14.8)$ & 15(34.1) & \\
\hline \multirow[t]{3}{*}{ Pruritus (48h) } & None & $54(66.7)$ & 17(38.6) & $0.039 *$ \\
\hline & Mild & 13(16.0) & 15(34.1) & \\
\hline & Moderate & 14(17.3) & $12(27.3)$ & \\
\hline \multirow[t]{2}{*}{ Anesthesia cost } & $\leq 1020$ & $47(58.0)$ & $23(52.3)$ & 0.791 \\
\hline & $>1020$ & $34(42.0)$ & $21(47.7)$ & \\
\hline Postoperative hospital stay & $\leq 5$ & $57(70.4)$ & $35(79.5)$ & 0.536 \\
\hline
\end{tabular}

None: VAS 0; Mild: VAS 1-3; moderate: VAS 4-6; severe: VAS 7-10; $24 \mathrm{~h}$ or $48 \mathrm{~h}: 24 \mathrm{~h}$ or $48 \mathrm{~h}$ after caesarean section; * $P<0.05$ 


\begin{tabular}{|c|c|c|c|c|}
\hline \multicolumn{2}{|l|}{ Variable } & \multirow{2}{*}{$\begin{array}{l}\text { Non-PD }(n=81) \\
24(29.6)\end{array}$} & \multirow{2}{*}{$\begin{array}{l}\text { PD (n= 44) } \\
9(20.5)\end{array}$} & \multirow[t]{2}{*}{$P$} \\
\hline & $>5$ & & & \\
\hline \multirow[t]{2}{*}{ Postpartum adverse events } & No & 76(93.8) & $36(81.8)$ & 0.204 \\
\hline & Yes & $5(6.2)$ & $8(18.2)$ & \\
\hline \multirow[t]{2}{*}{ Mastitis } & No & 71(87.7) & $38(86.4)$ & 1.000 \\
\hline & Yes & $10(12.3)$ & $6(13.6)$ & \\
\hline \multirow[t]{2}{*}{ Neonatal complications } & No & $70(86.4)$ & $33(75.0)$ & 0.362 \\
\hline & Yes & 11(13.6) & $11(25.0)$ & \\
\hline \multirow[t]{3}{*}{ Lumbago } & None & $54(66.7)$ & $23(52.3)$ & $0.049 *$ \\
\hline & Mild & 18(22.2) & $6(13.6)$ & \\
\hline & Moderate & $9(11.1)$ & 15(34.1) & \\
\hline \multirow[t]{2}{*}{ Place of "doing the month" } & Maternity Hotel & 14(17.3) & 14(31.8) & 0.252 \\
\hline & Home & $67(82.7)$ & $30(69.2)$ & \\
\hline Total dissatisfaction during & No & $64(78.8)$ & 18(40.9) & $0.002^{*}$ \\
\hline "doing the month" & Yes & 17(21.2) & $26(59.1)$ & \\
\hline $\begin{array}{l}\text { None: VAS 0; Mild: VAS 1-3; } \\
\text { caesarean section; }{ }^{*}<0.05\end{array}$ & te: VAS 4-6; s & VAS $7-10 ; 24 \mathrm{~h}$ & $8 \mathrm{~h}: 24 \mathrm{~h}$ or 4 & fter \\
\hline
\end{tabular}


Table 4

Association between PD and causes of dissatisfaction during "doing the month".

\begin{tabular}{|c|c|c|c|c|}
\hline Variable & & Non-PD $(n=81)$ & $P D(n=44)$ & $P$ \\
\hline \multirow[t]{2}{*}{ Dissatisfaction with place of "doing the month" } & No & $79(97.5)$ & $30(68.2)$ & $0.001 *$ \\
\hline & Yes & $2(2.5)$ & $14(31.8)$ & \\
\hline \multirow[t]{2}{*}{ Dissatisfaction with role transition } & No & $76(93.8)$ & 38 (86.4) & 0.399 \\
\hline & Yes & $5(6.2)$ & $6(13.6)$ & \\
\hline \multirow[t]{2}{*}{ Dissatisfaction with mother-in-law } & No & $78(96.3)$ & $30(68.2)$ & $0.002^{\star}$ \\
\hline & Yes & $3(3.7)$ & $14(31.8)$ & \\
\hline \multirow[t]{2}{*}{ Dissatisfaction with husband } & No & $79(97.5)$ & $31(70.5)$ & $0.001 *$ \\
\hline & Yes & $2(2.5)$ & $13(29.5)$ & \\
\hline \multirow[t]{2}{*}{ Dissatisfaction with baby for difficult to take care } & No & $70(86.4)$ & $33(75.0)$ & 0.190 \\
\hline & Yes & $11(13.6)$ & $11(25.0)$ & \\
\hline$\star P<0.05$ & & & & \\
\hline
\end{tabular}

\section{Risk Factors for PD 6 weeks postpartum}

During the initial data screening, 8 perioperative characteristics were identified as potential risk factors for PD 6 weeks postpartum. The univariate analyses found that the following parameters were risk factors for PD: mild pruritus at $48 \mathrm{~h}$ postpartum $(P=0.025)$, moderate postpartum lumbago $(P=0.027)$, moderate maternal total dissatisfaction during "doing the month" ( $P=0.001)$, dissatisfaction with mother-in-law $(P$ $=0.013)$ and husband $(P=0.042)$ during "doing the month". In addition, the univariate analyses showed that the following parameters were protective factors for PD: mild resting pain at $48 \mathrm{~h}$ postpartum $(P=$ $0.030)$, mild activity pain at 48 h postpartum $(P=0.005)$ and dissatisfaction with the place of "doing the month" $(P=0.044)$. (Table 5)

Results of the multivariate analysis indicated that there were 4 parameters recognized as independent risk factors or protective factors for PD: postpartum lumbago (OR: 5.68; 95\% Cl: 1.69-19.06; $P=0.005$ ), maternal total dissatisfaction during "doing the month" (OR 6.87, 95\% $\mathrm{Cl} 2.48-19.04 ; P=0.001$ ), and dissatisfaction with mother-in-law (OR: $3.22 ; 95 \% \mathrm{Cl}: 1.43-16.16 ; P=0.02)$ were independent risk factors for $\mathrm{PD}$, while mild activity pain (OR: $0.018 ; 95 \% \mathrm{Cl}: 0.01-0.25 ; P=0.003$ ) was independent protective factor for PD. (Table 5) 
Table 5

Univariate and multivariate logistic regression analysis of risk factors for PD.

\begin{tabular}{|c|c|c|c|c|}
\hline \multirow[t]{2}{*}{ Variable } & \multicolumn{2}{|c|}{$\begin{array}{l}\text { Univariate logistic } \\
\text { regression analysis }\end{array}$} & \multicolumn{2}{|c|}{$\begin{array}{l}\text { Multivariate logistic } \\
\text { regression analysis }\end{array}$} \\
\hline & OR $(95 \% \mathrm{Cl})$ & $P$ & OR $(95 \% \mathrm{Cl})$ & $P$ \\
\hline \multicolumn{5}{|c|}{ Resting pain(48h) } \\
\hline None & 1 & & 1 & \\
\hline Mild & $0.18(0.04,0.84)$ & $0.030^{*}$ & $0.018(0.01,0.25)$ & $0.003^{*}$ \\
\hline Moderate & $0.90(0.17,4.87)$ & 0.903 & & \\
\hline \multicolumn{5}{|c|}{ Activity pain(48h) } \\
\hline None & 1 & & 1 & \\
\hline Mild & $0.17(0.05,0.59)$ & $0.005^{\star}$ & $0.634(0.09,4.27)$ & 0.640 \\
\hline Moderate & $0.27(0.06,1.18)$ & 0.082 & & \\
\hline \multicolumn{5}{|c|}{ Pruritus (48h) } \\
\hline None & 1 & & 1 & \\
\hline Mild & $3.64(1.18,11.21)$ & $0.025^{\star}$ & $5.33(1.94,23.52)$ & 0.811 \\
\hline Moderate & $2.91(0.91,9.35)$ & 0.073 & & \\
\hline \multicolumn{5}{|l|}{ Lumbago } \\
\hline None & 1 & & 1 & \\
\hline Mild & $0.82(0.23,3.01)$ & 0.770 & & \\
\hline Moderate & $3.78(1.16,12.30)$ & $0.027^{*}$ & $5.68(1.69,19.06)$ & $0.005^{\star}$ \\
\hline \multicolumn{5}{|c|}{ Maternal total dissatisfaction during "doing the month" } \\
\hline No & 1 & & & \\
\hline Yes & $5.28(1.95,14.27)$ & $0.001^{\star}$ & $6.87(2.48,19.04)$ & $0.001 *$ \\
\hline \multicolumn{5}{|c|}{$\begin{array}{l}\text { Dissatisfaction with place of "doing } \\
\text { the month" }\end{array}$} \\
\hline No & 1 & & 1 & \\
\hline Yes & $0.04(0.01,0.37)$ & $0.044^{\star}$ & $0.329(0.03,1.07)$ & 0.361 \\
\hline \multicolumn{5}{|c|}{ Dissatisfaction with mother-in-law } \\
\hline No & 1 & & 1 & \\
\hline$\star P<0.05$ & & & & \\
\hline
\end{tabular}




\begin{tabular}{|lllll|}
\hline Variable & $\begin{array}{l}\text { Univariate logistic } \\
\text { regression analysis }\end{array}$ & \multicolumn{3}{l|}{$\begin{array}{l}\text { Multivariate logistic } \\
\text { regression analysis }\end{array}$} \\
\cline { 2 - 5 } & OR $(95 \%$ Cl) & $P$ & OR $(95 \%$ Cl $)$ & $P$ \\
\hline Yes & $2.96(1.26,15.67)$ & $0.013^{\star}$ & $3.22(1.43,16.16)$ & $0.020^{\star}$ \\
\hline Dissatisfaction with husband & & & & \\
\hline No & 1 & & & \\
\hline Yes & $1.82(1.13,16.29)$ & $0.042^{*}$ & $9.00(0.91,88.58)$ & 0.060 \\
\hline$* P<0.05$ & & & & \\
\hline 6 months postpartum follow-Up during COVID-19 pandemic
\end{tabular}

In February and March 2020, the outbreak of COVID-19 influenced Chinese people's lives, coinciding with when participants were at about 6 months postpartum. We telephoned to follow-up their psychological state and eighty-eight of them were contacted successfully. Fortunately, all women replied that they have peace of mind without too much worry because the Chinese government were strictly controlling the epidemic situation. Moreover, most of them had returned to their hometown with their baby, in isolation from the outside and with a small circle of life that made them feel safe. Besides, babies under 6 months of age rarely get sick due to getting antibodies from breast milk. The thing participants worried about most was the delay in routine vaccination of the infants, which had been permitted by epidemic prevention workers. Overall, the pandemic did not significantly influence participants' psychological state.

\section{Discussion}

This investigation showed that incidence of prenatal depression was $5.6 \%$, in the median split groups which rose markedly to $34.9 \%$ at 6 weeks postpartum, indicating that participants were strongly prone to emotional disorders in the early period after cesarean section. Chinese women tend to postpone marriage and childbearing contributing to older parturients and higher PD morbidity than before.

The etiology of PD is complex, while involvement of biological factors may play an important role in triggering PD ${ }^{[4]}$. In this study, we found no significant correlation between the occurrence of PD and the collected demographic factors, possibly because, in this single-center study in a Chinese public hospital, parturients were sociodemographically relatively homogenous. Additionally, with the improvement of economic conditions and preventive health care capabilities, complications among older pregnant women are gradually reducing and prenatal psychological preparation is becoming more adequate, which further reduces parturients' psychological burden.

Pain and depression are common in the population and co-morbid with each other ${ }^{[18,19]}$. A series of reports indicated that occurrence of psychological disorders was directly related to postoperative pain [20]. The incidence of depression in patients with higher pain levels can be twice as high as those without pain 
or with low pain levels ${ }^{[20]}$, although there is not a linear correlation between pain and overall depression [21]. It is possible that different depressive symptoms are related in different ways to postpartum pain [20]. Here, postoperative pain and pruritus were correlated with PD. Specifically, mild pain was negatively associated with PD morbidity, which has not been mentioned previously. Catecholamines including adrenaline and dopamine, which are kinds of neurochemical secreted during pain and stress ${ }^{[21]}$, play a role in making you happy and preventing depression ${ }^{[22]}$. Experimentally induced mild pain can diminish perception of pain by increasing pain thresholds which may contribute to depression prevention ${ }^{[23]}$. This may explain the low incidence of PD in parturients with mild postoperative pain, which would require further studies to confirm.

Social support plays an important role in promoting or mitigating the effect of postpartum mood disorders on mothers and children $[1,5]$. Indeed, compared with many other psychosocial risk factors, social support provided by maternal social networks and participants, such as financial support or assisting with infant care, had the greatest impact on PD [24]. The incidence of depression increased significantly at 6 weeks postpartum, which were strongly correlated with maternal total dissatisfaction during "doing the month". Among which dissatisfaction with mother-in-law was an independent risk factor of PD. The postpartum period is accompanied with numerous physical, emotional, financial, and social stressors, many of which may increase the risk of PD ${ }^{[25]}$. Social support and relevant skills training can lower the risk of PD by reducing the impact of stressors ${ }^{[26]}$. But always, families focused on the baby and ignored maternal emotional changes, thus increasing the psychological burden of the maternal. Especially while typical differences in lifestyle, parenting concept, and education mode between two generations led to a series of contradictions and conflicts existed further aggravating the occurrence of depression. Therefore, family members should focus on the psychological and emotional changes of the mother during "doing the month" period, and have more understanding and companionship for the mother. Besides, we should focus on the factors of maternal dissatisfaction, strengthen postpartum social support treatment, properly extend father's paternity leave to increase father's participation in taking care of baby, and reduce the occurrence of PD ${ }^{[27]}$.

Since the outbreak of COVID-19 pandemic worldwide this year, the domestic epidemic prevention policy is to stay at home and be far away from crowd resulting in limited social activities. New mothers had less opportunity to communicate with other mothers or friends and were harder to relieve their feelings. Besides, they even cannot go to see a doctor for neither infants' examination nor mothers' discomfort for the protection against COVID-19. Online meetings and telecommuting have become popular during the new crown epidemic. Similarly, psychological support treatment for patients with PD can also be treated with remote intervention and consultation, which not only saves time and costs but also reduces the risk of infection. At the same time, their friends can communicate and chat through online video calls, which is helpful for the relief of PD. A single prospective cohort study of telephone based interpersonal psychotherapy for PD has been published and found that remotely delivered therapies often represent a feasible alternative ${ }^{[28]}$. Although most studies have been conducted in non-clinical populations, the available evidence suggests that most remotely delivered therapies are superior to treatment as usual [29]. 


\section{Conclusions}

This study found that PD was related to postoperative pain, indicating that anesthesiologists have different degrees of influence on PD in many aspects, such as the choice of anesthesia methods, anesthetic drugs and intraoperative management. After operation, reasonable analgesia program is selected to carry out special postpartum pain clinic to provide relevant diagnosis and treatment for patients with postpartum low back pain, which plays a positive role in preventing PD. On the other hand, we should improve social awareness of the issues, notably the potential for difficulties between mother and mother-in-law whilst "doing the month", increase medical and health investment, and raise awareness of the importance of maternal mental health and a positive PD experience. There is further need for awareness of risk factors for PD amongst health care professionals and taking appropriate measures.

\section{Limitations}

This was a small, single center study. Measurement of key psychological variables including pain and dissatisfaction were relatively simplistic, using single Likkert scales rather than standard questionnaires. The findings may not apply to postpartum situations where there is no ERAS management.

\section{Abbreviations}

PD: Postpartum depression; EPDS: Edinburgh Postnatal Depression Scale; VAS: Visual analog scale; COVID-19: Corona Virus Disease 2019; ASA: American Society of Anesthesiologists; ERAS: Enhanced recovery after surgery; CSEA: Combined spinal and epidural anesthesia; BMI: Body mass index; SPSS: Statistical package for the social sciences.

\section{Declarations}

\section{Ethics approval and consent to participate}

The Research Ethics Committee at the Third Affiliated Hospital of Sun Yat-sen University, Guangzhou, China, reviewed and approved this prospective cohort study (201902-338-01). Written informed consent was obtained from all participants of the study.

\section{Consent for publication}

Not applicable.

\section{Availability of data and materials}

The data during the current study are available from the corresponding author on reasonable request. 


\section{Competing interest}

The authors declare that they have no competing interests.

\section{Funding}

This study was supported by the Natural Science Foundation of China (no. 82072218 and no. 82000597) and the Natural Science Foundation of Guangdong Province (No. 2020A1515010153, No. 2018A030313608, No. 2019A1515011766, and No. 2021A1515010255) for the analysis and interpretation of data and writing the manuscript.

\section{Acknowledgements}

The authors thank the patients and their families for participating in this study. We also thank Ms. Shuyi Zhong from School of Public Health, Sun Yat-sen University for her assistance with statistical analysis.

\section{Authors' contributions}

Contributors: LL and CC contributed equally to this study. YW, CL, SZ, and ZH conceived and designed the experiments. LL, CC, YY, MM, FH, and JP performed the experiments. YY analyzed the data. YW and LL draft the article and revise it critically for important intellectual content. YW and CL guided the study and all authors reviewed the manuscript.

\section{References}

1. Meltzer-Brody S, Howard LM, Bergink V, Vigod S, Jones I, Munk-Olsen T, et al. Postpartum psychiatric disorders. Nat Rev Dis Primers. 2018;4:18022.

2. Netsi E, Pearson RM, Murray L, Cooper P, Craske MG, Stein A. Association of persistent and severe postnatal depression with child outcomes. JAMA Psychiatry. 2018;75(3):247-253.

3. Howard LM, Molyneaux E, Dennis CL, Rochat T, Stein A, Milgrom J. Non-psychotic mental disorders in the perinatal period. Lancet. 2014;384(9956):1775-88.

4. Norhayati MN, Hazlina NH, Asrenee AR, Emilin WM. Magnitude and risk factors for postpartum symptoms: a literature review. J Affect Disord. 2015;175:34-52.

5. Yoneda K, Hababeh M, Kitamura A, Seita A, Kamiya Y. Prevalence and characteristics of Palestine refugee mothers at risk of postpartum depression in Amman, Jordan: a cross-sectional study. Lancet. 2021;398 Suppl 1:S28.

6. Ko JY, Rockhill KM, Tong VT, Morrow B, Farr SL. Trends in postpartum depressive symptoms- 27 States, 2004, 2008, and 2012. MMWR Morb Mortal Wkly Rep. 2017;66(6):153-158. 
7. US Preventive Services Task Force, Curry SJ, Krist AH, Owens DK, Barry MJ, Caughey AB, et al. Interventions to Prevent Perinatal Depression: US Preventive Services Task Force Recommendation Statement. JAMA. 2019;321(6):580-587.

8. Seeman MV. Cross-cultural evaluation of maternal competence in a culturally diverse society. Am J Psychiatry. 2008;165(5):565-8.

9. Ding G, Yu J, Vinturache A, Gu H, Lu M. Therapeutic Effects of the Traditional "Doing the Month" Practices on Postpartum Depression in China. Am J Psychiatry. 2018:175(11):1071-1072.

10. Kountanis JA, Muzik M, Chang T, Langen E, Cassidy R, Mashour GA, et al. Relationship between postpartum mood disorder and birth experience: a prospective observational study. Int J Obstet Anesth. 2020;11:44.

11. Meky HK, Shaaban MM, Ahmed MR, Mohammed TY. Prevalence of postpartum depression regarding mode of delivery: a cross-sectional study. J Matern Fetal Neonatal Med. 2020;33(19):3300-3307.

12. Guglielminotti J, Li G. Exposure to General Anesthesia for Cesarean Delivery and Odds of Severe Postpartum Depression Requiring Hospitalization. Anesth Analg. 2020;131(5):1421-1429.

13. Liu ZH, He ST, Deng CM, Ding T, Xu MJ, Wang L, et al. Neuraxial labour analgesia is associated with a reduced risk of maternal depression at 2 years after childbirth: A multicentre, prospective, longitudinal study. Eur J Anaesthesiol. 2019;36(10):745-754.

14. Babazade R, Vadhera RB, Krishnamurthy P, Varma A, Doulatram G, Saade GR, et al. Acute postcesarean pain is associated with in-hospital exclusive breastfeeding, length of stay and postpartum depression. J Clin Anesth. 2020; 62:109697.

15. Yu HY, Wang SY, Quan CX, Fang C, Luo SC, Li DY, et al. Dexmedetomidine Alleviates Postpartum Depressive Symptoms following Cesarean Section in Chinese Women: A Randomized PlaceboControlled Study. Pharmacotherapy. 2019;3910(10):994-1004.

16. Machado C, Lacerda ALT, Bressan RA, Noto C. Esketamine for Postpartum Suicidality Biol Psychiatry. 2021;89(6);e35-e36.

17. Pan J, Hei Z, Li L, Zhu D, Hou H, Wu H, et al. The Advantage of Implementation of Enhanced Recovery After Surgery (ERAS) in Acute Pain Management During Elective Cesarean Delivery: A Prospective Randomized Controlled Trial. Ther Clin Risk Manag. 2020;16:369-378.

18. Yin Y, Zhang L, Xiao H, Wen CB, Dai YE, Yang G, et al. The pre-amputation pain and the postoperative deafferentation are the risk factors of phantom limb pain: a clinical survey in a sample of Chinese population. BMC Anesthesiol. 2017;17(1):69.

19. Uysal Ai, Altıparmak B, Korkmaz Toker M, Dede G, Sezgin Ç, Gümüş Demirbilek S.The effect of preoperative anxiety level on mean platelet volume and propofol consumption. BMC Anesthesiol. 2020;20(1):34.

20. Angst F, Verra ML, Lehmann S, Aeschlimann A, Angst J. Refined Insights Into the Pain-Depression Association in Chronic Pain Patients. Clin J Pain. 2008; 24(9):808-816.

21. Arribas-Blázquez M, Olivos-Oré LA, Barahona MV, Wojnicz A, Pascual RD, Muela MS, et al. The Adrenal Medulla Modulates Mechanical Allodynia in a Rat Model of Neuropathic Pain. Int J Mol Sci. 
2020;21(21):8325.

22. El-Marasy SA, El Awdan SA, Hassan A, Ahmed-Farid OA, Ogaly HA. Anti-depressant effect of cerebrolysin in reserpine-induced depression in rats: Behavioral, biochemical, molecular and immunohistochemical evidence. Chem Biol Interact. 2021;334:109329.

23. Lautenbacher $\mathrm{S}$, Krieg JC. Pain perception in psychiatric disorders: a review of the literature. J Psychiatr Res. 1994;28(2):109-22.

24. Xie RH, Yang J, Liao S, Xie H, Walker M, Wen SW. Prenatal family support, postnatal family support and postpartum depression. Aust N Z J Obstet Gynaecol. 2010:50(4);340-5.

25. Dennis CL, Dowswell T. Psychosocial and psychological interventions for preventing postpartum depression. Cochrane Database Syst Rev. 2013; 2(2):CD001134.

26. Agler RA, Zivich PN, Kawende B, Behets F, Yotebieng M. Postpartum depressive symptoms following implementation of the 10 steps to successful breastfeeding program in Kinshasa, Democratic Republic of Congo: A cohort study. PLoS Med. 2021;18(1):e1003465.

27. Johansen SL, Robakis TK, Williams KE, Rasgon NL. Management of perinatal depression with nondrug interventions. BMJ. 2019;364:I322.

28. Posmontier B, Neugebauer R, Stuart S, Chittams J, Shaughnessy R. Telephone-Administered Interpersonal Psychotherapy by Nurse-Midwives for Postpartum Depression. J Midwifery Womens Health. 2016;61(4):456-66.

29. Deligiannidis KM, Kroll-Desrosiers AR, Mo S, Nguyen HP, Svenson A, Jaitly N, et al. Peripartum neuroactive steroid and gamma-aminobutyric acid profiles in women atrisk for postpartum depression. Psychoneuroendocrinology. 2016;70:98-107.

\section{Figures}




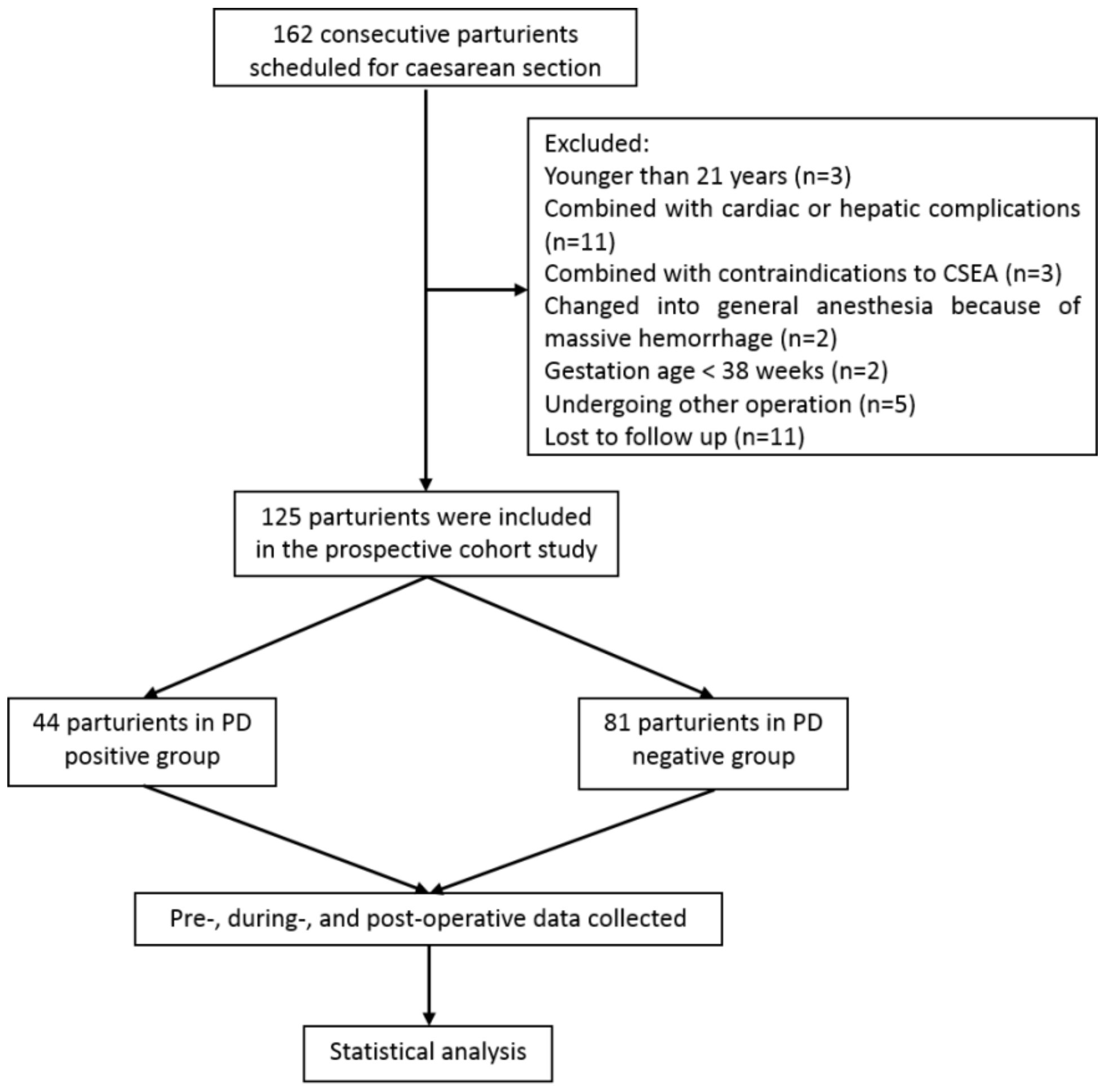

Figure 1

Study population and exclusion criteria in the current prospective cohort study 
Fig. 2

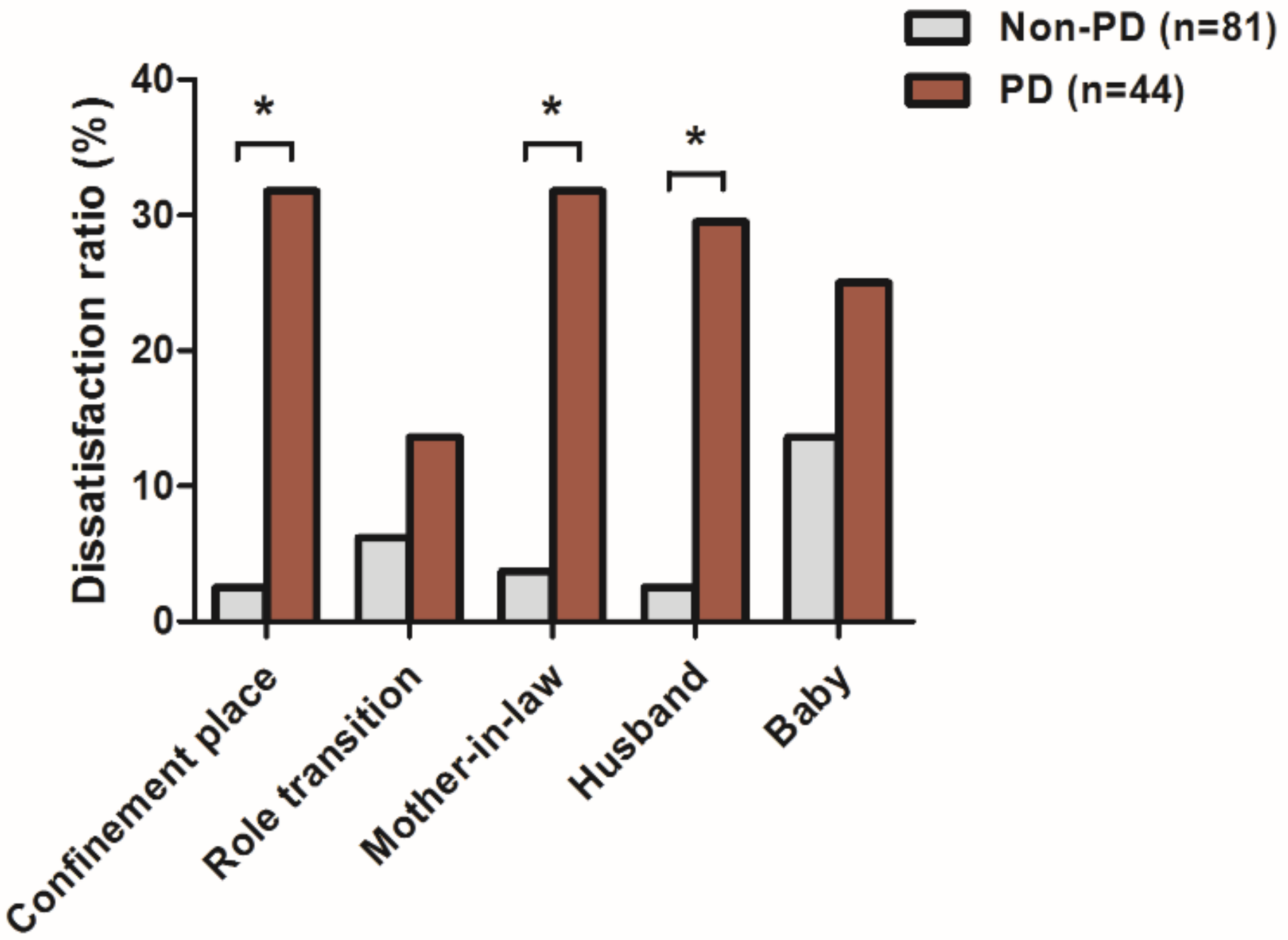

Figure 2

Association between PD and causes of dissatisfaction during "doing the month". *P $<0.05$. The dissatisfaction ratio is the number dissatisfied in each group divided by the total number in each group, expressed as a percentage. 